\title{
Isotopic Characterization of Shallow Groundwater Resources in Lagos Coastal Basin, Nigeria
}

\author{
K.O. IBRAHIM ${ }^{1 *}$ AND M.A. YUSUF ${ }^{2}$
}

${ }^{1}$ Department of Geology and Mineral Sciences, Faculty of Physical Sciences, University of Ilorin, P.M.B.1515, Ilorin, Nigeria (*correspondence: ibrakeo@yahoo.com) ${ }^{2}$ Department of Geology and Mineral Sciences, Faculty of Physical Sciences, University of Ilorin, P.M.B 1515, Ilorin, Nigeria

\section{Research Methodology}

This study employed stable and radioactive isotopic measurements to unravel the source of recharge and residence time of shallow groundwater system in Lagos Coastal Basin. Thirty (30) samples for stable isotopes of ${ }^{2} \mathrm{H}$ and ${ }^{18} \mathrm{O}, 21$ samples for radioactive tritium and 9 -samples for ${ }^{14} \mathrm{C}$ and ${ }^{13} \mathrm{C}$ isotopes were collected and analyzed. Figure 1 below shows the plot of $\delta^{2} \mathrm{H}$ against $\delta^{18} \mathrm{O}$.

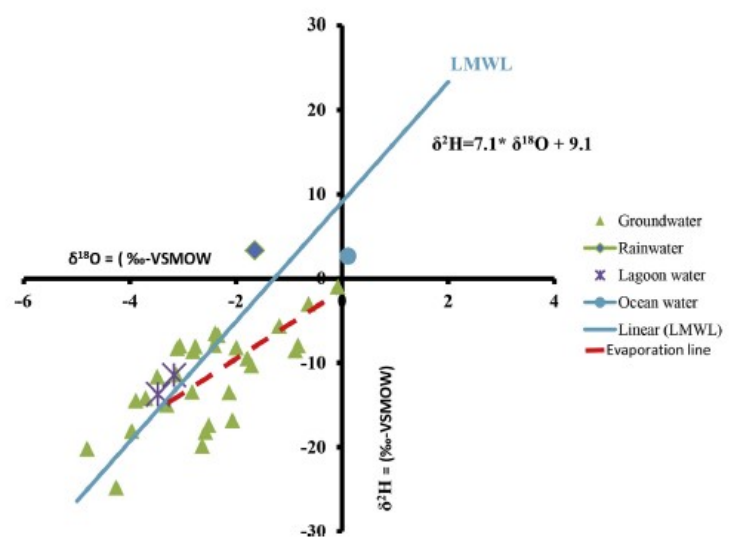

Figure 1: Plot of $\delta^{2} \mathrm{H}$ versus $\delta^{18} \mathrm{O}(\%)$ for groundwater in Lagos Coastal Basin

\section{Discussion of Results}

The environmental isotope plot in Figure 1 portrays that the samples fell above, below and along the global meteoric waterline (GMWL), indicating that the groundwater samples were of meteoric origin following Craig (1961).

\section{References}

Craig (1961) Science 133, 1833- 1834. 